\title{
Structural Stereochemistry of Androstene Hormones Determines Interactions with Human Androgen, Estrogen, and Glucocorticoid Receptors
}

\author{
Thomas L. Shaak, ${ }^{1,2,3}$ Dayanjan S. Wijesinghe, ${ }^{4,5}$ Charles E. Chalfant, ${ }^{4,5,6}$ \\ Robert F. Diegelmann, ${ }^{2,5}$ Kevin R. Ward, ${ }^{7}$ and Roger M. Loria ${ }^{2,8}$ \\ ${ }^{1}$ Department of Integrative Life Sciences, Virginia Commonwealth University, Richmond, VA 23298, USA \\ ${ }^{2}$ Virginia Commonwealth University Reanimation Engineering Science Center (VCURES), \\ Virginia Commonwealth University, Richmond, VA 23298, USA \\ ${ }^{3}$ Department of Biochemistry, Virginia Commonwealth University, 1101 E. Marshall Street, Sanger Hall, \\ Room 2-004, Richmond, VA 23298, USA \\ ${ }^{4}$ Hunter Holmes McGuire VA Medical Center, Richmond, VA 23249, USA \\ ${ }^{5}$ Department of Biochemistry and Molecular Biology, Virginia Commonwealth University, Richmond, VA 23298, USA \\ ${ }^{6}$ Massey Cancer Center, Richmond, VA 23298, USA \\ ${ }^{7}$ Michigan Critical Injury and Illness Research Center, Department of Emergency Medicine, University of Michigan, \\ Ann Arbor, MI 48109, USA \\ ${ }^{8}$ Department of Microbiology, Immunology, Pathology and Emergency Medicine, Virginia Commonwealth University, \\ Richmond, VA 23298, USA
}

Correspondence should be addressed to Thomas L.Shaak; tshaak28@gmail.com

Received 17 January 2013; Revised 27 February 2013; Accepted 14 March 2013

Academic Editor: Patrick Bednarski

Copyright (c) 2013 Thomas L. Shaak et al. This is an open access article distributed under the Creative Commons Attribution License, which permits unrestricted use, distribution, and reproduction in any medium, provided the original work is properly cited.

DHEA, 17 $\alpha$-AED, $17 \beta$-AED, and 17 $\beta$-AET exhibit strong biological activity that has been attributed to androgenic, estrogenic, or antiglucocorticoid activity in vivo and in vitro. This study compared DHEA, $17 \alpha$-AED, $17 \beta$-AED, and $17 \beta$-AET for their ability to activate the human AR, ER, and GR and determine the relative androgenicity, estrogenicity, and glucocorticoid activity. The results show that, at the receptor level, these androstene hormones are weak AR and even weaker ER activators. Direct androstene hormone activation of the human AR, ER $\alpha$, and $\operatorname{ER} \beta$ may not be essential for their biological function. Similarly, these hormones indirectly activated the human GR, only in the presence of high dexamethasone concentrations. These results underscore the major difference between androstene hormone interactions with these nuclear receptors and their biological effects.

\section{Introduction}

DHEA, an androstene hormone, has been shown to possess a wide range of beneficial biological effects mainly attributed to immune system modulation [1]. DHEA is metabolized into more active metabolites, that is, $17 \beta$-AED and $17 \beta$-AET, as well as testosterone and estradiol $[1,2] .17 \beta$-AED and $17 \beta$ AET have been reported to prevent the morbidity and mortality of otherwise lethal infections [3, 4], potentiate lymphocyte activation, and counteract the immune suppressive action of hydrocortisone [5-7], thus leading to beneficial effects in diverse human diseases including resistance to infection, neuroprotection, wound healing, diabetes, hepatic injury, cardiovascular disease, and cancer [8-10].

$17 \alpha$-AED mediates autophagy of glial and breast cancers and apoptosis of myeloid tumor cells [11-13]. 17 $\beta$-AED and $17 \alpha$-AED naturally exist in epimeric forms based on whether the hydroxyl group is above $(\beta)$ or below $(\alpha)$ the $\Delta^{5}$ cycloperhydrophenanthrene ring. Addition of a hydroxyl group at the $\mathrm{C} 7$ position to $17 \beta$-AED results in the formation 
of $\Delta^{5}$-androstene- $3 \beta, 7 \beta, 17 \beta$-triol (17 $\beta$-AET). The biological activities of $17 \alpha$-AED, $17 \beta$-AED, and $17 \beta$-AET have exhibited a structure-activity relationship that depends on the orientation and location of the hydroxyl groups [13].

Androstene hormones (AH) have been shown to promulgate their biological effects in many different animal models including mice, rats, monkeys, and some specific human tissues. Reports have associated the mechanism of action of androstene hormone metabolites with androgen, estrogen, and glucocorticoid receptor activity [14-16]. Adrenal hormones have been shown to activate both androgen and estrogen constructs. In this regard, it has been documented that $17 \beta$-AED can activate the AR in prostate tissue in the presence of commonly used antiandrogens [17]. Inhibitors of both the androgen receptor and the estrogen receptors demonstrated that $\mathrm{AR}$ and $\mathrm{ER} \beta$ receptors combine to affect gene transcription [18]. Additionally, $17 \beta$-AED was recently shown to be a part of an anti-inflammatory mechanism that utilizes the ER $\beta$ [19]. 17 $\beta$-AED and 17 $\beta$-AET have been documented in vitro and in vivo to oppose the action of hydrocortisone indicating that there may be crosstalk with the GR $[6,20,21]$.

DHEA has been shown to possess weak androgenicity and estrogenicity [22]. Because $17 \alpha$-AED, $17 \beta$-AED, and $17 \beta-$ AET are more potent metabolites of DHEA that exhibit strong biological activity that could be attributed to androgenic, estrogenic, or antiglucocorticoid activity in vivo and in vitro, it was advantageous to identify whether or not this is directly mediated by the human ER, AR, and GR at the cellular level. Additionally, androstenediol has been modeled as a chemical with a $3 \beta$-hydroxy and a saturated $A$ ring which can act as an estrogen [23]. Consequently, we compared DHEA, $17 \alpha$-AED, $17 \beta$-AED, and $17 \beta$-AET in the Indigo Biosciences nuclear receptor assay system for their ability to activate the human $\mathrm{AR}, \mathrm{ER}$, and GR and determine the relative androgenicity and estrogenicity of these androstene hormone derivatives.

\section{Materials and Methods}

2.1. Nuclear Receptor Transactivation Assays. Nuclear receptor transactivation assays were obtained from Indigo Biosciences (State College, PA, USA) and were utilized to assess the activation of human $\mathrm{AR}, \mathrm{ER} \beta$, and $\mathrm{ER} \alpha$. receptors. Briefly, stocks of the compounds tested were prepared and diluted in a medium provided by the manufacturer. Cell medium was tested for hormone activity by mass spectrometry (Section 2.3). Frozen reporter cells provided in the assay kit were thawed and compound dilutions were added immediately. Cells were incubated for 24 hours and the activation response was measured on a luminometer (Perkin-Elmer, MA, USA). The cells consisted of non-human mammalian cells engineered by Indigo Biosciences to provide constitutive high-level expression of full length, unmodified human androgen receptor (NR3C4), human estrogen receptor 1 (NR3A1), human estrogen receptor 2 (NR3A2), and full length, human glucocorticoid receptor (NR3C1).

The nonhuman mammalian reporter cells included a luciferase reporter gene functionally linked to a human nuclear receptor-responsive promoter. The cells are engineered so that only interactions with the human receptor will induce luciferase expression in the treated reporter cells to quantitate nuclear receptor activation. Positive control ligand performance was measured by the manufacturer and provided in the technical manuals thus allowing accurate comparison for assay performance. Additionally, the control ligands of the receptors (testosterone, 17 $\beta$-estradiol, and dexamethasone) were tested on the same test plates $(n=3$ to allow statistical analysis) with the androstene hormones and controls.

2.2. Preparation of Stock Hormone Solutions. Stock solutions of $17 \beta$-AED, $17 \alpha$-AED, and testosterone (Sigma-Aldrich, St. Louis, MO, USA) were prepared by dissolving the compounds into $100 \%$ ethanol to a final $50 \mathrm{mM}$ stock solution concentration; $17 \beta$-AET was also a stock solution of $50 \mathrm{mM}$ but was dissolved into 1:1 DMSO/ethanol because of solubility issues. Cyproterone acetate (Sigma-Aldrich) was diluted with $100 \%$ ethanol and used at a $10 \mathrm{uM}$ concentration. All stock solutions were diluted to final concentrations using the dilution fluid provided in each kit. All tests were performed with negative controls on the same plate and contained media alone and media containing the same amount of ethanol utilized in the stock solutions. All assay control results were in accordance with the stated technical performance specifications.

2.3. Mass Spectrometry. LC-MS/MS analyses of the steroid hormones were carried out using a Shimadzu Nexera UPLC device coupled (Shimadzu Corp, Kyoto, Japan) to AB Sciex (Foster City, CA, USA) 5500 Hybrid Triple Quadrupole Linear Ion Trap Mass Spectrometer operating in multiple reaction monitoring mode. Nitrogen produced by a highpurity nitrogen generator (PEAK Scientific Instruments Ltd, Chicago, Il, USA) was used as curtain, nebulizer, and collision gases. Unit mass resolution was set in both mass-resolving quadrupole Q1 and Q3. Ionization of the analytes was carried out using an APCI source. Multiple MRM transitions were selected for each analyte to eliminate ambiguity in analyte identification. For all steroids other than AED, 25 microliters of the media was directly injected onto a 2.1 $\times 50 \mathrm{~mm} 2.6 \mu \mathrm{m} \mathrm{C18} \mathrm{reverse} \mathrm{phase} \mathrm{column} \mathrm{(Phenomenex)}$ and was separated via a linear gradient of water: methanol 98:2 (Solvent A) to methanol: water 70:30 (Solvent B). Both solvents contained $5 \mathrm{mM}$ ammonium formate with $1 \%$ formic acid. Separation of $17 \alpha$-AED and $17 \beta$-AED was carried out using $2.1 \times 150 \mathrm{~mm} 2.6 \mu \mathrm{m} \mathrm{C18}$ reverse phase column (Phenomenex) and was done using same Solvent A as above and $98: 2$ methanol: water with $5 \mathrm{mM}$ ammonium formate and $1 \%$ formic acid as Solvent B. Steroid hormones were detected using precursor product. MRM pairs are as follows: DHEA (271-213, 271-197), androstenetriol (307-158, 307-254), androstenediol (291-95, 291-159, 291-255), testosterone (28997, 289-109), androstenedione (287-97, 287-109), and $17 \beta-$ estradiol (273-107, 273-135, 273-77). Where there were multiple transitions, the dominant peak was used in the analysis. 
All analytes demonstrated a minimal limit of detection of at least $0.6 \mathrm{nM}$.

2.3.1. Cellular Uptake of Androstene Hormones and Normalization of Transactivation Assay Results. It was relevant to determine the relative uptake of each androstene hormone in the Indigo Assay System. Cells and cell medium utilized in the assays were provided by the manufacturer (Indigo Biosciences). The following components were found to be below the limit of detection in the cells and cell medium: DHEA, 17 $\beta$-estradiol, androstenedione, testosterone, $17 \alpha$ AED, 17 $\beta$-AED, and 17 $\beta$-AET. LCMS data was utilized as a ratio between the background subtracted signal (area under the curve of the LCMS trace) at time zero and 24 hours for each analyte investigated. The ratios were then utilized to create normalization factors for the cellular uptake of $17 \alpha$-AED, $17 \beta$-AED, and $17 \beta$-AET as compared to DHEA. The normalization factors were DHEA: 1, 17 $\alpha$-AED: 1.71, $17 \beta$-AED: 1.85 , and $17 \beta$-AET: 2.40 , respectively. Background activity due to cells, media, and vehicle was subtracted before the data were normalized.

2.3.2. Metabolism of Androstene Hormones. The cell medium was analyzed before and after incubation with assay cells. Mass spectroscopy (Section 2.3) was utilized to detect androstenedione, $17 \beta$-AED, $17 \alpha$-AED, and $17 \beta$-AET, as well as testosterone and $17 \beta$-estradiol that were expressed in the medium. Approximately $9 \%$ of DHEA was metabolized to $17 \beta$-AED after a 24 -hour incubation with assay cells. No other DHEA metabolites were detected. Mass spectroscopy did not detect any metabolites of the other androstene hormones in the media after a 24-hour incubation period. The mass spectrometry data show that DHEA was minimally metabolized to $17 \beta$-AED in this cell construct, but not to testosterone or $17 \beta$-estradiol (Section 2.3.2). 17 $\beta$-AED, $17 \beta$ AET, and $17 \alpha$-AED were not metabolized.

2.4. Statistical Analysis. All statistical analyses were performed using SigmaPlot version 12 (SSI, San Jose, CA, USA). Hormone $\mathrm{EC}_{50}$ level and the estrogen receptor alpha activation statistical analyses were performed with a Student's $t$-test while all other hormone activation statistical comparisons were performed with a one-way ANOVA. $P$ value levels < 0.05 were considered significant. Statistics on test groups were done before normalization to cellular uptake and were performed between test groups and controls.

\section{Results and Discussion}

3.1. Androstene Hormone Structures. The hormones that were used in this study are listed in Figure 1. The structures demonstrate the similarities and unique characteristics of each androstene hormone. The main differences are the orientation of the hydroxyl group at position $\mathrm{C} 17$ for $17 \alpha$-AED and $17 \beta-\mathrm{AED}$, the orientation and position of the hydroxyl group at position $\mathrm{C} 7$ for $17 \beta$-AET, and the ketone group at position 17 for DHEA. $17 \alpha$-AED and $17 \beta$-AED are chemically identical except for the placement of the hydroxyl group in relation to (above or below) the $\Delta^{5}$ cycloperhydrophenanthrene ring. All adrenal hormones in this study, with the exception of DHEA, possess hydroxyl groups in the C3 and C17 position with $17 \alpha$-AED having the $\mathrm{C} 17$ hydroxyl group in the $(\alpha)$ position. This position at $\mathrm{C} 17$ results in remarkable biological actions $[11,13]$ while the hydroxyl group at C3 was shown not to influence the biological activity [24].

3.2. Androstene Hormone Activation of the Human AR. The data demonstrate that both the orientation of the hydroxyl at position $\mathrm{C} 17$ and the addition of the hydroxyl at position C7 affected the ability of $17 \beta$-AED, $17 \beta$-AET, and $17 \alpha$-AED to activate the human AR construct (Figure 2 ). The AR construct contains a luciferase reporter gene that is functionally linked to an AR responsive promoter. The luciferase reading is utilized as a surrogate measure for $\mathrm{AR}$ binding. The $\mathrm{EC}_{50}$ was calculated for testosterone as the $50 \%$ activation point. $\mathrm{EC}_{50}$ values for the androstene hormones and testosterone were calculated (Table 1) and compared utilizing the ratio of the androstene hormone $\mathrm{EC}_{50}$ to testosterone $\mathrm{EC}_{50}$ (relative androgenicity). All of the androstene hormones tested showed a significant $(P<0.001)$ reduced androgenicity when compared to testosterone (Table 1 ). $17 \beta$-AED had only $1 / 5$ th the ability of testosterone to activate the androgen receptor. Changing the orientation of the $\mathrm{C} 17$ hydroxyl group on $17 \alpha$ AED resulted in a further reduction to $1 / 60$ th the activity as compared to testosterone. Addition of the hydroxyl group to the $\mathrm{C} 7$ position further reduced the ability to activate the human AR construct to 1/1326th as that of testosterone. The androstene hormone activation of the human AR was rank ordered based on strength of activation. The rank order was $17 \beta$-AED $\gg 17 \alpha$-AED $\gg 17 \beta$-AET (Figure 2 ). DHEA binding to the AR was excluded from these experiments since its androgenicity has been reported previously [22].

3.3. Androstene Hormone Activation of the Human ER $\beta$ and ER $\alpha$ Receptors. The data demonstrate that both the orientation of the hydroxyl at position $\mathrm{C} 17$ and the addition of the hydroxyl at position $\mathrm{C} 7$ affected the ability of DHEA, $17 \beta$-AED, $17 \beta$-AET, and $17 \alpha$-AED to activate the human $\operatorname{ER} \beta$ construct (Figure 3 ). The ER construct contains a luciferase reporter gene that is functionally linked to an ER responsive promoter. The luciferase reading is utilized as a surrogate measure for ER binding. The $\mathrm{EC}_{50}$ was calculated for $17 \beta$-estradiol as the $50 \%$ activation point. $\mathrm{EC}_{50}$ values for the androstene hormones and $17 \beta$-estradiol were calculated (Table 2) and compared utilizing the ratio of the androstene hormone $\mathrm{EC}_{50}$ to $17 \beta$-estradiol $\mathrm{EC}_{50}$ (relative estrogenicity). All of the tested androstene hormones demonstrated a significantly $(P<0.001)$ decreased estrogenicity compared to $17 \beta$-estradiol (Table 2 ). $17 \beta$-AED had only $1 / 282$ nd the ability of $17 \beta$-estradiol to activate the $\mathrm{ER} \beta$. The orientation change of the hydroxyl group at position $\mathrm{C} 17$ of $17 \beta$-AED to the $(\alpha)$ position resulted in $17 \alpha$-AED possessing $1 / 7609$ th the ability of $17 \beta$-estradiol to activate the $\mathrm{ER} \beta$ receptor as $17 \beta$-estradiol. This represents a drastic decrease in estrogenicity from the $17 \beta$-AED epimer. The presence of the hydroxyl group at C7 of $17 \beta$-AET resulted in $1 / 587$ th the ability to activate the $\operatorname{ER} \beta$. 
<smiles>CC12CC[C@@H](O)CC1=CCC1C2CCC2(C)C1CC[C@@H]2O</smiles>

(a)<smiles>CC12CC[C@H](O)CC1=CCC1C2CCC2(C)C1CC[C@@H]2O</smiles>

$17 \beta$-AED

(b)

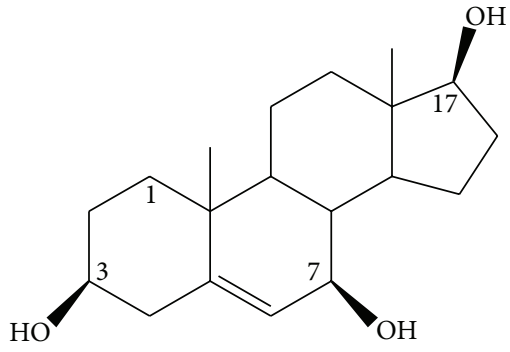

$17 \beta$-AET

(c)<smiles>CC12CCC3C(CC=C4C[C@@H](O)CCC43C)C1CCC2=O</smiles>

(d)

FigurE 1: The structures of the androstene hormones. The androstene hormones are shown with the $\Delta^{5}$ cycloperhydrophenanthrene ring. All steroids have a C3 hydroxyl group in the $(\beta)$ beta position. The $\mathrm{C} 7$ hydroxyl group of androstenetriol is in the $\beta$-position. The C17 hydroxyl of androstenediol epimers are in either the $(\alpha)$ alpha or $(\beta)$ beta position.

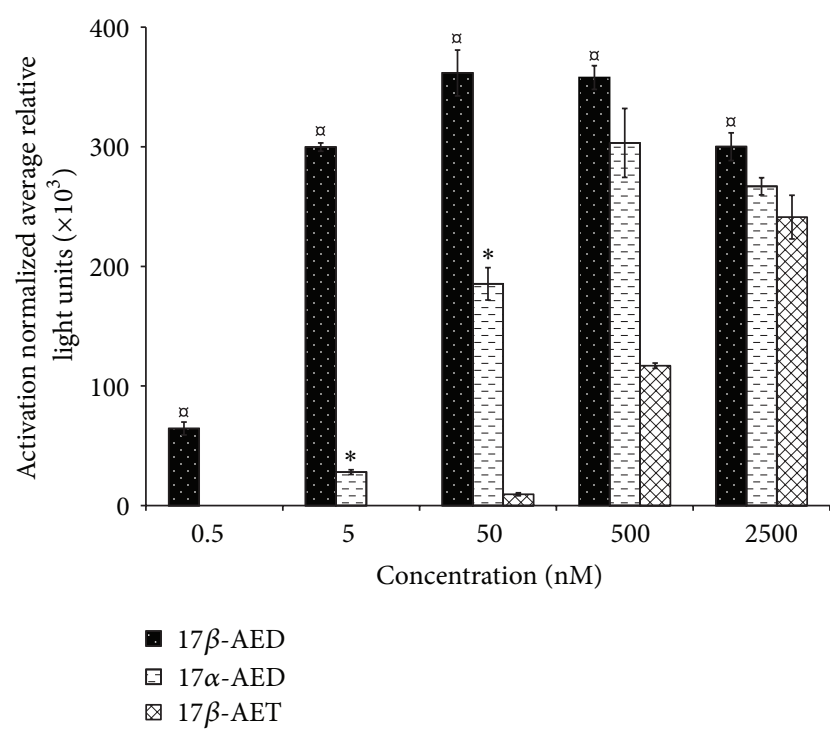

FIGURE 2: Androstene hormone activation of the human androgen receptor. Reporter cells were treated with androstene hormone metabolites $(n=3)$, incubated for 24 hours, and then assayed for luciferase activity. Androstene hormone activity was normalized to cellular uptake (Section 2.3.1). Error bars, \pm 1 SD. Statistical significance, $P<0.001$ from all less activating androstene hormone metabolites ( $x), P<0.001$ from less activating androstene hormone metabolites $(*)$.
TABLE 1: Relative androgenicity of androstene hormones.

\begin{tabular}{lccc}
\hline Hormone & $\mathrm{EC}_{50}(\mathrm{nM})$ & Androgenicity & $P$ value \\
\hline Testosterone & 0.35 & 1 & 1 \\
$\Delta^{5}$-Androstene-3 $\beta, 17 \beta$-diol & 1.8 & $1 / 5$ & $<0.001$ \\
$\Delta^{5}$-Androstene-3 $\beta, 17 \alpha$-diol & 21 & $1 / 60$ & $<0.001$ \\
$\Delta^{5}$-Androstene-3 $\beta, 7 \beta, 17 \beta$-triol & 464 & $1 / 1326$ & $<0.001$ \\
\hline
\end{tabular}

The $\mathrm{EC}_{50}$ was calculated as the $50 \%$ activation point. The androgenicity is the testosterone $\mathrm{EC}_{50}$ divided by the androstene hormone $\mathrm{EC}_{50}$. This data does not normalize the cellular uptake of androstene hormones.

DHEA, with a ketone group in the $\mathrm{C} 17$ position, possessed $1 / 3543$ rd the ability to activate the $\mathrm{ER} \beta$.

The rank order of androstene hormone activation on the human $\operatorname{ER} \beta$ receptor can be displayed as follows: $17 \beta$ AED $>17 \beta$-AET $>$ DHEA $>17 \alpha$-AED (Figure 3). These androstene hormones also specifically activated the human $\mathrm{ER} \beta$ receptor and demonstrated the crucial effect of the $(\beta)$ C17 hydroxyl group. $17 \beta$-AED and $17 \alpha$-AED activated the $\mathrm{ER} \beta$ receptor 2 and 3 orders of magnitude lower, respectively, than $17 \beta$-estradiol (Table 2). The $17 \beta$-AED demonstrated an estrogenicity of 1/1176 when assayed on the human ER $\alpha$. Activation of the ER $\alpha$ receptor by $17 \beta$-AED did not become apparent until the concentration reached $25 \mathrm{nM}$ (Figure 4) which was 3 orders of magnitude lower than $17 \beta$-estradiol, further demonstrating the weak estrogenicity displayed by these hormones at the level of the ERs. Finally, it should be 


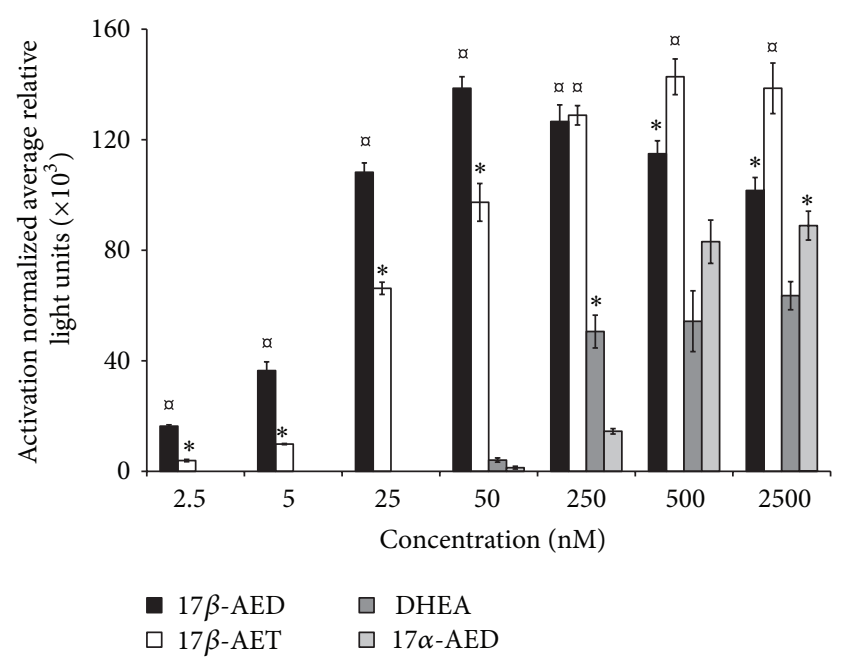

FIGURE 3: Androstene hormone activation of the human estrogen receptor beta. Reporter cells were treated with androstene hormones $(n=3)$, incubated for 24 hours, and then assayed for luciferase activity. Androstene hormone activity was normalized to cellular uptake (Section 2.3.1). Error bars, \pm 1 SD. Statistical significance, $P<0.001(\mathbb{a})$ versus androstene hormone metabolites in the same treatment group, $P<0.001(*)$ versus lower reacting androstene hormones in the same treatment group.

TABLE 2: Relative estrogenicity of androstene hormones.

\begin{tabular}{lccc}
\hline Hormone & $\mathrm{EC}_{50}(\mathrm{nM})$ & Estrogenicity & $P$ value \\
\hline $17 \beta$-Estradiol & 0.046 & 1 & 1 \\
$\Delta^{5}$-Androstene-3 $\beta, 17 \beta$-diol & 13 & $1 / 282$ & $<0.001$ \\
$\Delta^{5}$-Androstene-3 $\beta, 7 \beta, 17 \beta$-triol & 27 & $1 / 587$ & $<0.001$ \\
DHEA & 163 & $1 / 3543$ & $<0.001$ \\
$\Delta^{5}$-Androstene-3 $\beta, 17 \alpha$-diol & 350 & $1 / 7609$ & $<0.001$ \\
\hline
\end{tabular}

The $\mathrm{EC}_{50}$ was calculated as the $50 \%$ activation point. The estrogenicity is the $17 \beta$-estradiol $\mathrm{EC}_{50}$ divided by the androstene hormone $\mathrm{EC}_{50}$. This data does not normalize the cellular uptake of androstene hormones.

noted that the androstene hormones only weakly activated the AR and were even weaker activators of the human ERs.

3.4. Androstene Hormones Activation of the Human Glucocorticoid Receptor (GR). 17 $\beta$-AED and especially $17 \beta$-AET are known to produce significantly affected glucocorticoid activity in vivo $[6,20,21]$. Therefore, the human GR construct response to $17 \beta$-AED, $17 \beta$-AET, DHEA, and $17 \alpha$-AED alone and in combination with dexamethasone was evaluated. The results showed that dexamethasone alone activated the human GR while $17 \beta$-AED, $17 \beta$-AET, DHEA, and $17 \alpha$-AED alone were negative at all concentrations tested (Figure 5). The human GR was then tested for activity with androstene hormones in the presence of dexamethasone. Unexpectedly, at suprapharmacological levels of dexamethasone there was a considerable activation of the human GR by $1 \mu \mathrm{M}$ of each of the androstene hormones, which was greater than with dexamethasone alone with a higher activity when dexamethasone concentration was increased from $333 \mathrm{pM}$ to $1000 \mathrm{pM}$ (Figure 6).

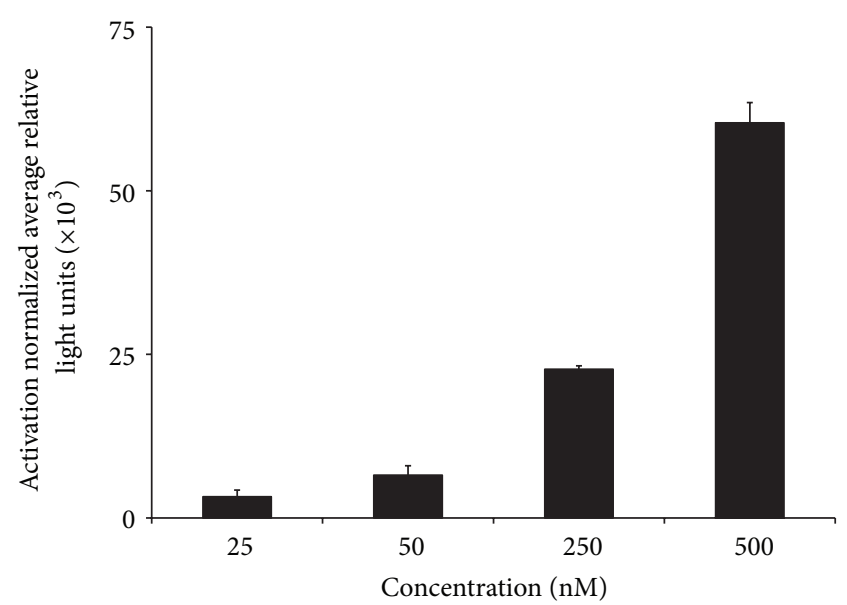

- $17 \beta$-AED

FIGURE 4: $17 \beta$-AED activation of the human estrogen receptor alpha. Reporter cells were treated with 17 $\beta$-AED $(n=3)$, incubated for 24 hours, and then assayed for luciferase activity. $17 \beta$-AED activity was normalized to cellular uptake (Section 2.3.1), error bars, \pm 1 SD.

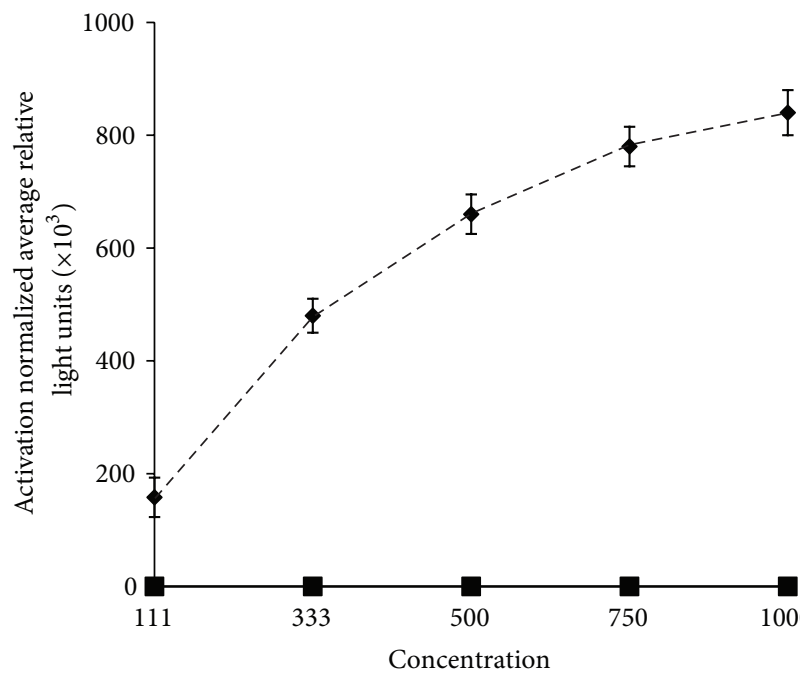

- - Dexamethasone (pM)

$\rightarrow$ Androstene hormones (nM)

FIGURE 5: Dexamethasone or androstene hormone activation of the human glucocorticoid receptor. Reporter cells were treated with dexamethasone or androstene hormones alone $(n=3)$, incubated for 24 hours, and then assayed for luciferase activity. Androstene hormones are DHEA, $17 \beta$-AED, $17 \alpha$-AED, and $17 \beta$ - AET. Error bars, $\pm 1 \mathrm{SD}$.

The rank order of activation of the dexamethasone-bound human GR in the presence of the androstene hormones is as follows: $17 \beta$-AET $>17 \beta$-AED $>17 \alpha$-AED $>$ DHEA. These data demonstrate that the $\mathrm{C} 7$ hydroxyl present in $17 \beta$-AET produced the strongest activation of the dexamethasonebound human GR. The $(\beta)$ C17 hydroxyl of $17 \beta$-AED produced a stronger activation than did the $(\alpha)$ C17 hydroxyl of $17 \alpha$-AED. Thus, while $17 \beta$-AED and $17 \alpha$-AED produced 


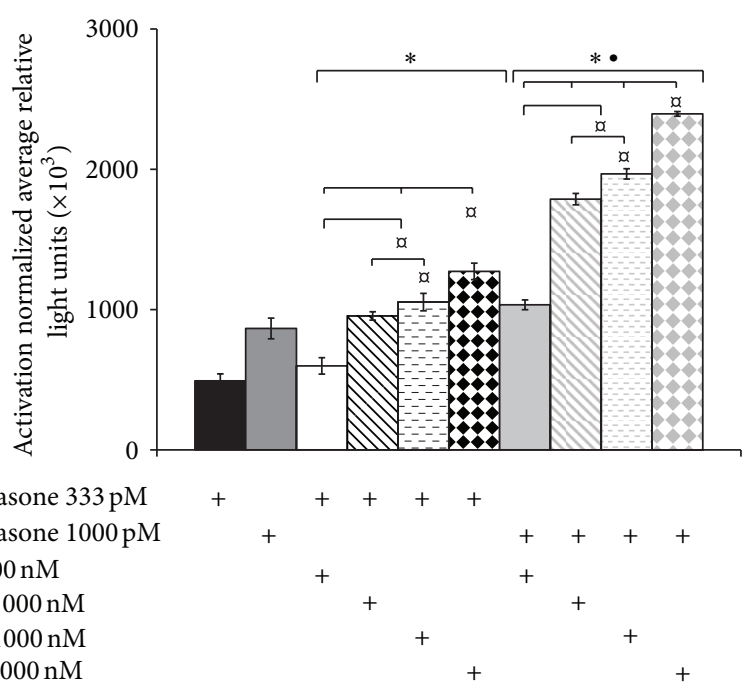

FIGURE 6: Androstene hormones and dexamethasone activation of the human GR. Reporter cells were treated with dexamethasone alone or a combination of dexamethasone and androstene hormone, incubated for 24 hours, and then assayed for luciferase activity $(n=3)$. Androstene hormone activity was normalized to cellular uptake (Section 2.3.1). Error bars, \pm 1 SD. Statistical significance, $P$ is at least $<0.05$ from other androstene hormone metabolites within the dexamethasone concentration treatment group (a), $P$ is at least $<0.05$ versus control ( $*$ ), $P$ is at least $<0.05$ from $333 \mathrm{pM}$ dexamethasone treatment group $(\bullet)$.

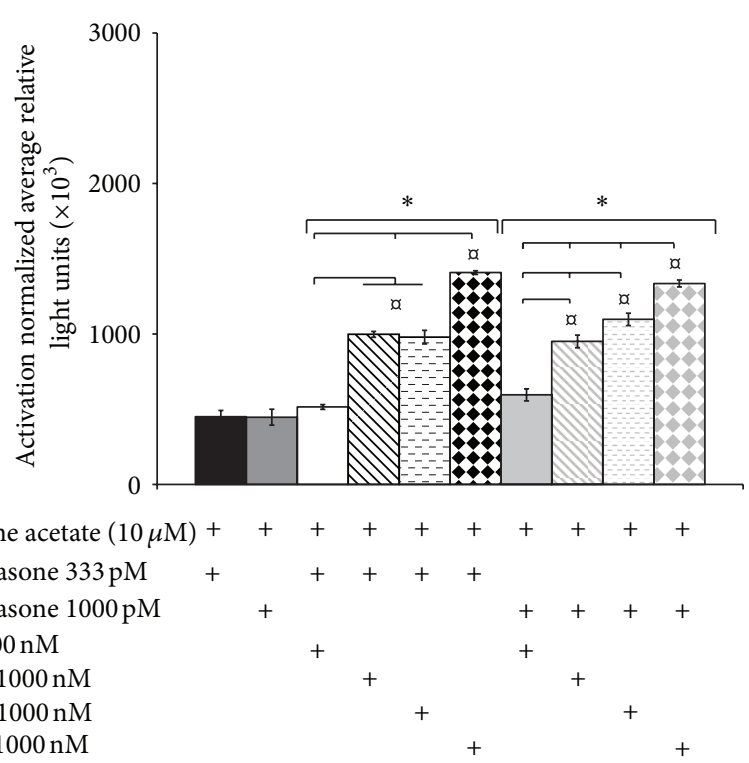

FIgURE 7: Androstene hormone and dexamethasone activation of the human GR in the presence of cyproterone acetate. Reporter cells were treated with dexamethasone and cyproterone acetate alone or androstene hormones with dexamethasone and cyproterone acetate $(n=3)$, incubated for 24 hours, and then assayed for luciferase activity. Androstene hormone activity was normalized to cellular uptake (Section 2.3.1). Error bars, \pm 1 SD. Statistical significance, $P$ is at least $<0.05$ from other androstene hormone metabolites within the treatment group ( $a$ ), $P<0.05$ from controls $(*)$.

unique activation of the dexamethasone-bound human GR, the effect of the C17 hydroxyl group conformation was less apparent. DHEA, which has the keto group in the C17 position, possessed the least ability to activate the dexamethasone-bound human GR.

We next tested these effects with the dexamethasone inhibitor, cyproterone acetate, to see if we could reduce or eliminate the dexamethasone and androstene hormone activation of the human GR. Cyproterone acetate was selected as the inhibitor because of its unique glucocorticoid receptor inhibiting properties [25]. Cyproterone effectively inhibited the activation of the human GR by dexamethasone (Figure 7). Cyproterone acetate at a concentration of $10 \mathrm{uM}$ was tested in the presence of the androstene hormones alone $(1.0 \mathrm{uM})$ and there was no activation detected (data not shown). Androstene hormones, however, in the presence of 
cyproterone and dexamethasone exhibited different levels of activation that were significantly increased above the dexamethasone/cyproterone alone controls (Figure 7). These results are of particular clinical significance because it demonstrates that high-dose dexamethasone alters the human GR to interact with other biologically active hormones at the receptor level. Importantly, dexamethasone is known to cause adverse effects in humans [26].

The rank order of activation of the dexamethasone/ cyproterone acetate-bound human GR in the presence of these androstene hormones is as follows: $17 \beta$-AET $>17 \beta$ AED $>17 \alpha$-AED $>$ DHEA. This rank order of activation on the inhibited human GR was the same as that of the uninhibited human GR indicating that the interaction of the androstene hormones and the dexamethasone/cyproteronebound human GR was not disrupted. Since cyproterone acetate is a passive inhibitor of the human GR and opposes dexamethasone through an overlapping steroid scaffold mechanism, this suggests that the androstene hormone activation is mediated by an interaction that occurs outside the dexamethasone/cyproterone acetate-bound complex [25]. Additionally, the presence of dexamethasone-bound human GR is required to observe activation by the androstene hormones while cyproterone acetate alone does not mediate this effect. Together these data suggest an indirect activation of the ligand-bound human GR by $17 \beta$-AET, $17 \beta$-AED, $17 \alpha$ AED, and DHEA.

\section{Conclusion}

This report indicates that the position of the hydroxyl group at $\mathrm{C} 17$ and/or the addition of the hydroxyl group at position C7 significantly affected the ability of $17 \beta$-AET, $17 \beta$-AED, $17 \alpha$-AED, and DHEA to interact with the human estrogen, androgen, and ligand-bound glucocorticoid receptors. $17 \beta$ AET, $17 \beta$-AED, $17 \alpha$-AED, and DHEA were shown to interact either directly or indirectly with the human AR, ER, and GR. Importantly, $17 \beta$-AET, $17 \beta$-AED, $17 \alpha$-AED, and DHEA were shown to possess weak androgenicity and even weaker estrogenicity at the receptor level. Clinically, this is beneficial because the biological effects can be realized without unwanted androgenic or estrogenic effects.

In a stark contrast to the minimal receptor activation of $\mathrm{AR}, \mathrm{ER}$, and GR, these same androstene hormones produce striking biological effects in vitro and in vivo which have been attributed to activity with the AR, ER, or GR. Clearly, these effects may not be mediated by the direct androstene hormone interaction with the human $\mathrm{AR}, \mathrm{ER} \alpha, \mathrm{ER} \beta$, and GR. Indeed, the biological mechanism, may not require AR or ER to achieve significant effects [27, 28]. Furthermore, the interaction with dexamethasone is indirect, occurs at high doses, and is not abolished by cyproterone acetate. Taken together, the data shows that interactions of $17 \beta$-AET, $17 \beta$-AED, $17 \alpha$-AED, and DHEA with the human AR, ER $\alpha$, $\mathrm{ER} \beta$, and GR are directed by the structure activity of these androstene hormones with minimal androgenic, estrogenic, or glucocorticoid effects and accentuates the need to further uncover the implied yet unidentified main mechanism(s) of action of these important adrenal hormones.

\section{Abbreviations}

\begin{tabular}{|c|c|}
\hline 17 $\beta$-AED: & $\Delta^{5}$-androstene- $3 \beta, 17 \beta$-diol \\
\hline $17 \alpha$-AED: & $\Delta^{5}$-androstene- $3 \beta, 17 \alpha$-diol \\
\hline $17 \beta$-AET: & $\Delta^{5}$-androstene- $3 \beta, 7 \beta, 17 \beta$-trio \\
\hline Androstene hormones: & $\begin{array}{l}17 \beta \text {-AED, } 17 \alpha \text {-AED, } 17 \beta \text {-AET, } \\
\text { DHEA }\end{array}$ \\
\hline $\begin{array}{l}\text { Androstene hormone } \\
\text { metabolites: }\end{array}$ & $17 \beta$-AED, $17 \alpha$-AED, $17 \beta$-AET \\
\hline DHEA: & Dehydroepiandrosterone \\
\hline AR: & Androgen receptor \\
\hline $\mathrm{ER} \alpha:$ & Estrogen receptor alpha \\
\hline $\mathrm{ER} \beta:$ & Estrogen receptor beta \\
\hline GR: & Glucocorticoid receptor \\
\hline$(\alpha)$ & Alpha position \\
\hline$(\beta):$ & Beta position. \\
\hline
\end{tabular}

\section{Acknowledgments}

This work was performed in conjunction with the Virginia Commonwealth University Reanimation Engineering Science Center (VCURES), Virginia Commonwealth University, Richmond, VA, USA. This work was supported by the US Army Medical Research and Materiel Command under Grant no. W81XWH-07-1-08-1-0483. As well as a gift to Roger M. Loria from the SCDR Cancer Research Fund, this work was also supported by a Career Development Award (CDA1) from the Department of Veterans Affairs (DSW), research grants from the Veteran's Administration (VA Merit Award BX001792 to C.E.C. and a Research Career Scientist Award to C. E. Chalfant); from the National Institutes of Health via HL072925 (C. E. Chalfant), CA154314 (C.E.C.); from the US-Israel Binational Science Foundation via BSF\#2011380 (C.E.C) and NH1C06-RR17393 (to Virginia Commonwealth University for renovation). The views expressed in this paper are those of the author and do not reflect the official policy or position of the United States Air Force, Department of Defense, or the US Government.

\section{References}

[1] J. S. Dillon, "Dehydroepiandrosterone, dehydroepiandrosterone sulfate and related steroids: their role in inflammatory, allergic and immunological disorders," Current Drug Targets, vol. 4, no. 3, pp. 377-385, 2005.

[2] R. Oberbeck and P. Kobbe, "DEhydroepiandrosterone (DHEA): a steroid with multiple effects. Is there any possible option in the treatment of critical illness?" Current Medicinal Chemistry, vol. 17, no. 11, pp. 1039-1047, 2010.

[3] R. M. Loria and D. A. Padgett, "Androstenediol regulates systemic resistance against lethal infections in mice," Annals of the New York Academy of Sciences, vol. 685, pp. 293-295, 1993.

[4] R. M. Loria and D. A. Padgett, "Mobilization of cutaneous immunity for systemic protection against infections," Annals of the New York Academy of Sciences, vol. 650, pp. 363-366, 1992.

[5] R. M. Loria, D. A. Padgett, and P. N. Huynh, "Regulation of the immune response by dehydroepiandrosterone and its metabolites," Journal of Endocrinology, vol. 150, pp. S209-S220, 1996. 
[6] R. M. Loria, "Antiglucocorticoid function of androstenetriol," Psychoneuroendocrinology, vol. 22, supplement 1, pp. S103-S108, 1997.

[7] D. A. Padgett, R. M. Loria, and J. F. Sheridan, "Endocrine regulation of the immune response to influenza virus infection with a metabolite of DHEA-androstenediol," Journal of Neuroimmunology, vol. 78, no. 1-2, pp. 203-211, 1997.

[8] F. Svec and J. R. Porter, "The actions of exogenous dehydroepiandrosterone in experimental animals and humans," Proceedings of the Society for Experimental Biology and Medicine, vol. 218, no. 3, pp. 174-191, 1998.

[9] C. D. Santos, M. P. A. Toldo, F. H. Santello, M. D. V. Filipin, V. Brazão, and J. C. do Prado Júnior, "Dehydroepiandrosterone increases resistance to experimental infection by Trypanosoma cruzi," Veterinary Parasitology, vol. 153, pp. 238-243, 2008.

[10] V. R. Feeser, N. B. Menke, K. R. Ward, R. M. Loria, and R. F. Diegelmann, "Androstenediol reverses steroid-inhibited wound healing: biomedical hypothesis article," Wound Repair and Regeneration, vol. 17, no. 5, pp. 758-761, 2009.

[11] P. Huynh and R. Loria, "Contrasting effects of alpha- and betaandrostenediol on oncogenic myeloid cell lines in vitro," Journal of Leukocyte Biology, vol. 62, no. 2, pp. 258-2267, 1997.

[12] M. R. Graf, W. Jia, and R. M. Loria, "The neuro-steroid, $3 \beta$ androstene $17 \alpha$ diol exhibits potent cytotoxic effects on human malignant glioma and lymphoma cells through different programmed cell death pathways," British Journal of Cancer, vol. 97, no. 5, pp. 619-627, 2007.

[13] M. R. Graf, W. Jia, M. L. Lewbart, and R. M. Loria, "The antitumor effects of androstene steroids exhibit a strict structureactivity relationship dependent upon the orientation of the hydroxyl group on carbon-17," Chemical Biology and Drug Design, vol. 74, no. 6, pp. 625-629, 2009.

[14] H. Miyamoto, S. Yeh, H. Lardy, E. Messing, and C. Chang, " $85-$ Androstenediol is a natural hormone with androgenic activity in human prostate cancer cells," Proceedings of the National Academy of Sciences of the United States of America, vol. 95, no. 19, pp. 11083-11088, 1998.

[15] R. Hackenberg, I. Turgetto, A. Filmer, and K. D. Schulz, "Estrogen and androgen receptor mediated stimulation and inhibition of proliferation by androst-5-ene- $3 \beta, 17 \beta$-diol in human mammary cancer cells," Journal of Steroid Biochemistry and Molecular Biology, vol. 46, no. 5, pp. 597-603, 1993.

[16] C. C. Head, M. J. Farrow, J. F. Sheridan, and D. A. Padgett, "Androstenediol reduces the anti-inflammatory effects of restraint stress during wound healing," Brain, Behavior, and Immunity, vol. 20, no. 6, pp. 590-596, 2006.

[17] P. Marwah, A. Marwah, H. A. Lardy, H. Miyamoto, and C. Chang, "C19-Steroids as androgen receptor modulators: design, discovery, and structure-activity relationship of new steroidal androgen receptor antagonists," Bioorganic and Medicinal Chemistry, vol. 14, no. 17, pp. 5933-5947, 2006.

[18] J. T. Arnold, X. Liu, J. D. Allen, H. Le, K. K. McFann, and M. R. Blackman, "Androgen receptor or estrogen receptor- $\beta$ blockade alters DHEA-, DHT-, and E2-induced proliferation and PSA production in human prostate cancer cells," Prostate, vol. 67, no. 11, pp. 1152-1162, 2007.

[19] K. Saijo, J. G. Collier, A. C. Li, J. A. Katzenellenbogen, and C. K. Glass, "An ADIOL-ER $\beta$-CtBP transrepression pathway negatively regulates microglia-mediated inflammation," Cell, vol. 145, no. 4, pp. 584-595, 2011.

[20] D. A. Padgett and R. M. Loria, "In vitro potentiation of lymphocyte activation by dehydroepiandrosterone, androstenediol, and androstenetriol," The Journal of Immunology, vol. 153, no. 4, pp. 1544-1552, 1994.

[21] R. M. Loria and D. A. Padgett, "Androstenediol regulates systemic resistance against lethal infections in mice," Archives of Virology, vol. 127, no. 1-4, pp. 103-115, 1992.

[22] F. Chen, K. Knecht, E. Birzin et al., "Direct agonist/antagonist functions of dehydroepiandrosterone," Endocrinology, vol. 146, no. 11, pp. 4568-4576, 2005.

[23] M. E. Baker, "Co-evolution of steroidogenic and steroidinactivating enzymes and adrenal and sex steroid receptors," Molecular and Cellular Endocrinology, vol. 215, no. 1-2, pp. 5562, 2004.

[24] R. M. Loria and M. R. Graf, " $17 \alpha$-androstenediol-mediated oncophagy of tumor cells by different mechanisms is determined by the target tumor," Annals of the New York Academy of Sciences, vol. 1262, no. 1, pp. 127-133, 2012.

[25] C. Honer, K. Nam, C. Fink et al., "Glucocorticoid receptor antagonism by cyproterone acetate and RU486," Molecular Pharmacology, vol. 63, no. 5, pp. 1012-1020, 2003.

[26] K. Matsumoto, H. Yamasaki, S. Akazawa et al., "High-dose but not low-dose dexamethasone impairs glucose tolerance by inducing compensatory failure of pancreatic $\beta$-cells in normal men," Journal of Clinical Endocrinology and Metabolism, vol. 81, no. 7, pp. 2621-2626, 1996.

[27] P. N. Huynh, W. H. Carter, and R. M. Loria, "17 Alpha androstenediol inhibition of breast tumor cell proliferation in estrogen receptor-positive and -negative cell lines," Cancer Detection and Prevention, vol. 24, no. 5, pp. 435-444, 2000.

[28] R. Loria, M. Graf, W. Jia, and T. Powell, "5-androstene $3 \beta, 17 \alpha$ diol induces autophagic cell death of human breast cancer cells and enhances radiation cytotoxicity," Journal of Cancer Therapeutics and Research, vol. 1, no. 1, 25 pages, 2012. 

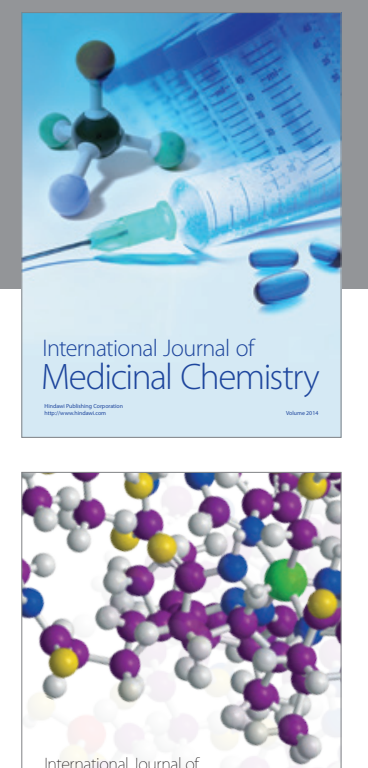

\section{Carbohydrate} Chemistry

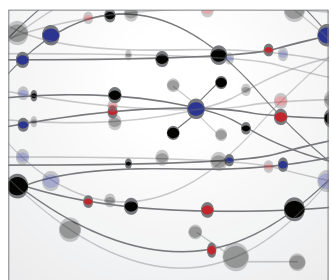

The Scientific World Journal
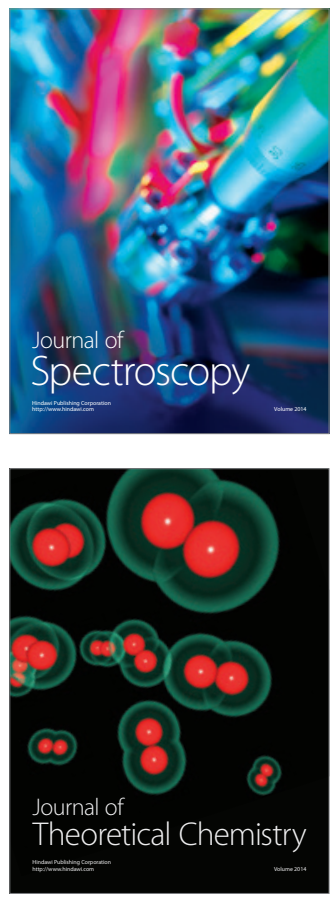
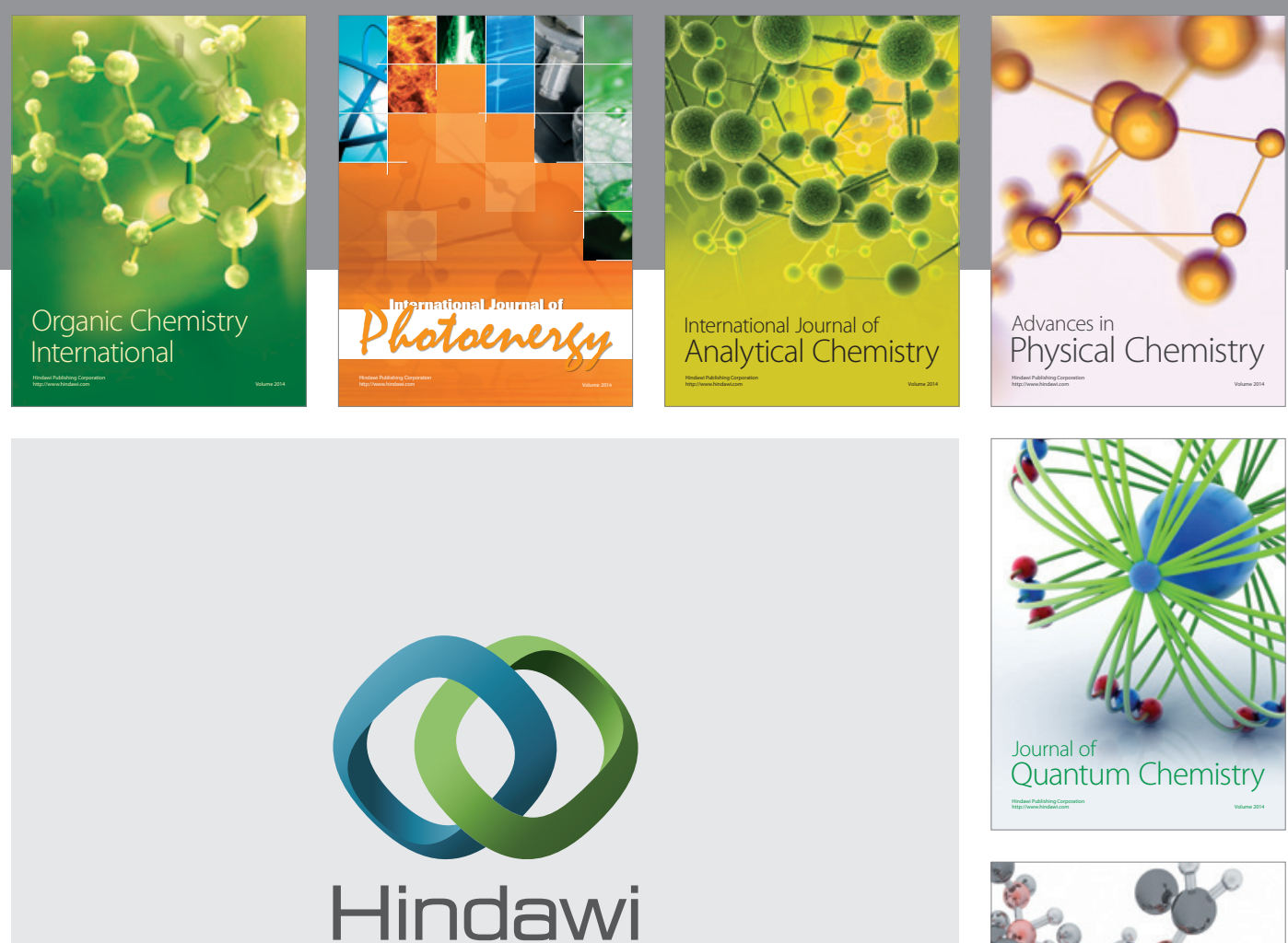

Submit your manuscripts at

http://www.hindawi.com

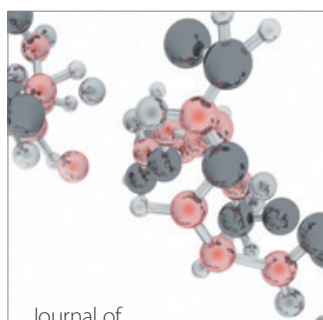

Analytical Methods

in Chemistry

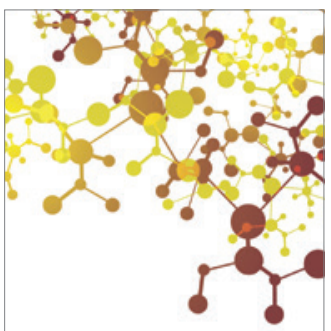

Journal of

Applied Chemistry

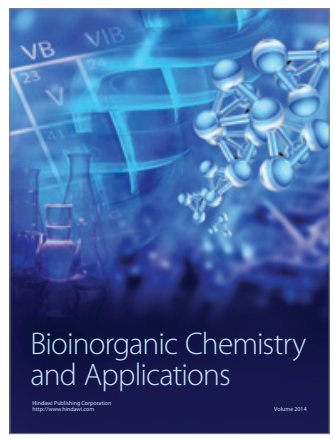

Inorganic Chemistry
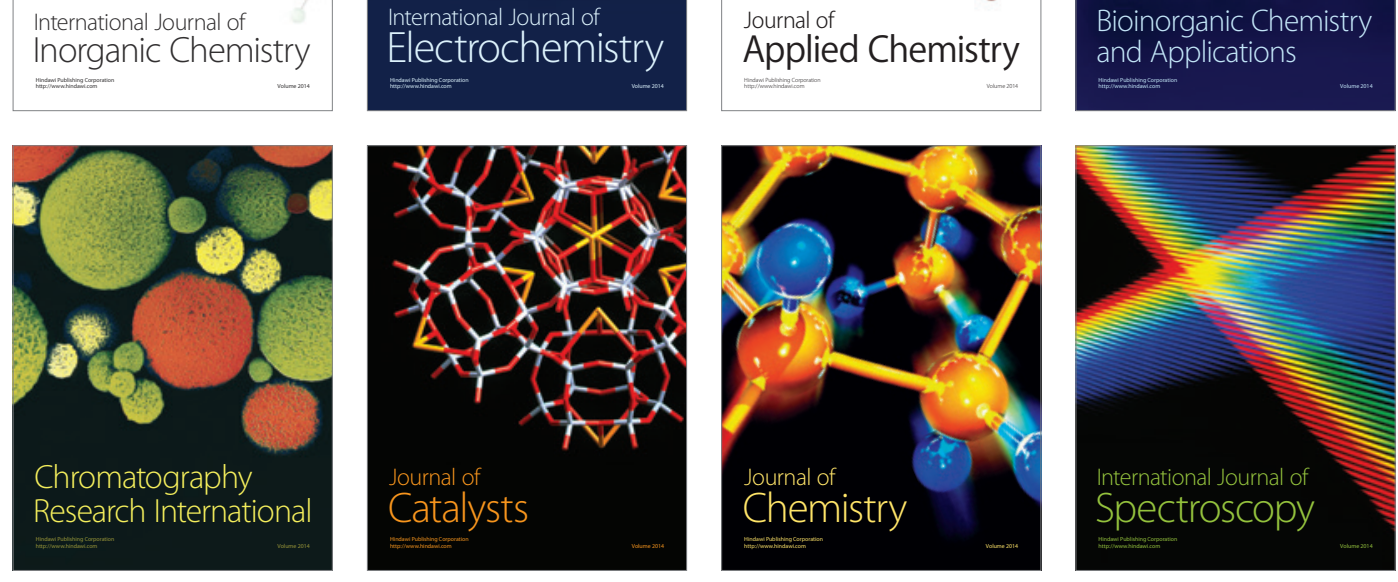